\title{
Plasma heme oxygenase- 1 is decreased in peripheral artery disease patients
}

\author{
SALVATORE SANTO SIGNORELLI ${ }^{1}$, GUIDO LI VOLSI ${ }^{2}$, VALERIO FIORE ${ }^{1}$, MARCO MANGIAFICO ${ }^{1}$, \\ IGNAZIO BARBAGALLO ${ }^{3}$, ROSALBA PARENTI ${ }^{2}$, MANFREDI RIZZO ${ }^{4}$ and GIOVANNI LI VOLTI ${ }^{2}$
}

\author{
Departments of ${ }^{1}$ Clinical and Experimental Medicine, ${ }^{2}$ Biomedical and Biotechnological Science and ${ }^{3}$ Drug Science, \\ University of Catania, I-95100 Catania; ${ }^{4}$ Biomedical Department of Internal Medicine and Medical Specialties, \\ University of Palermo, I-90139 Palermo, Italy
}

Received February 17, 2016; Accepted May 12, 2016

DOI: $10.3892 / \mathrm{mmr} .2016 .5644$

\begin{abstract}
Peripheral artery disease (PAD) is a common manifestation of atherosclerosis. A number of emerging risk factors, including oxidative stress biomarkers, free radicals and heat shock proteins, may add to the established risk factors for cardiovascular disease (CVD). The present study assessed surrogate markers of oxidative stress, including total reduced glutathione (GSH), lipid hydroperoxides $(\mathrm{LOOH})$, isoprostanes, heme oxygenase-1 (HO-1) and metabolic biomarkers, such as adiponectin and lactate, in PAD patients $(n=27)$. Healthy age-matched volunteers $(n=27)$ served as controls. GSH and LOOH were evaluated by measuring total thiol groups and iron oxidation, respectively, by spectrophotometric analysis. Adiponectin, isoprostanes and HO-1 levels were determined using commercially available ELISA kits and lactate level was determined colorimetrically. Results from patients with PAD demonstrated no significant difference in GSH content and $\mathrm{LOOH}$ formation when compared with healthy controls $(5.1 \pm 7.6$ vs. $6.9 \pm 9.1 \mathrm{nmol} / \mathrm{ml}$ and $6.8 \pm 14.2$ vs. $8.3 \pm 14.9 \mathrm{nmol} / \mathrm{ml}$, respectively), however, isoprostanes were demonstrated to be significantly reduced $(3.8 \pm 4.8 \mathrm{pg} / \mathrm{ml}$ vs. $120 \pm 91 \mathrm{pg} / \mathrm{mll} ; \mathrm{P}<0.001)$. Furthermore, HO-1, a protective heat shock protein, was significantly reduced in PAD patients $(0.8 \pm 0.7$ vs. $3.4 \pm 1.3 \mathrm{ng} / \mathrm{ml} ; \mathrm{P}<0.001)$. Adiponectin, an antiatherogenic adipokine, was not significantly different between the two groups $(1.4 \pm 0.2$ vs. $1.5 \pm 0.5 \mu \mathrm{g} / \mathrm{ml})$, whereas serum lactate was significantly higher in PAD patients compared with controls $(0.11 \pm 0.01$ vs. $0.1 \pm 0.01 \mathrm{mM} ; \mathrm{P}<0.05)$. Using multivariate analysis, HO-1, hypertension, smoking and dyslipidemia were indicated to be independently associated with the presence of PAD, while only ankle-brachial
\end{abstract}

Correspondence to: Professor Salvatore Santo Signorelli, Department of Clinical and Experimental Medicine, University of Catania, 5 Piazza Santa Maria di Gesù, I-95100 Catania, Italy E-mail: ssignore@unict.it

Key words: peripheral arterial disease, oxidative stress, heme-oxygenase, isoprostanes, biomarker index was an independent predictor of severity of PAD. The oxidative pathway may be partially involved in the onset and progression of PAD and may represent a target to reduce the risk of ischemic events.

\section{Introduction}

Peripheral artery disease (PAD) affects 3-20\% of the population $>50-55$ years old and is associated with a high cardiovascular (CV) mortality (1). PAD remains a major clinical problem as it is considered a marker of the extent of atherosclerosis. Furthermore, a large number of PAD patients suffer from multiple arterial co-morbidities leading to high $\mathrm{CV}$ mortality or a poor prognosis within a short time frame (2-4).

In the United States of America, Medicare spends $\sim 3.9$ billion dollars annually on treatment associated with PAD; this is more than that spent on other CV diseases, including myocardial infarction, angina, aortic aneurysm and carotid disease, or on high blood pressure, cigarette smoking, diabetes mellitus and hypercholesterolemia (3). Different pathophysiological mechanisms underlie the development of atherosclerotic plaque and the subsequent development of $\mathrm{CV}$ disease, these mechanisms include inflammation, platelet activation, endothelial damage, the proliferation/apoptosis balance of smooth muscle cells, and oxidative stress (5). The association between oxidative stress and $\mathrm{CV}$ disease has been demonstrated by numerous previous studies $(6,7)$. These studies have demonstrated that oxidative stress may have an etiological role and be used as a biomarker for atherosclerosis. When oxidative stress occurs, cells trigger a series of biochemical cascades in an attempt to counteract the altered redox balance and restore homeostasis (8). Among these biochemical responses, the heme oxygenase (HO) system has been suggested to be key $(7,9)$. HO-1 is an intracellular enzyme that catalyzes the breakdown of heme to carbon monoxide, ferrous iron and biliverdin (10). However, numerous other effects not directly associated with erythrocyte metabolism but of potential relevance to the $\mathrm{CV}$ system have been reported, including protection from ischemia/reperfusion $(10,11)$, blood pressure regulation (12), inflammation (13-15) and in angiogenesis (16,17). In addition, the presence of HO-1 has been demonstrated in various intracellular and extracellular compartments, suggesting that this 
protein may have other properties independent of its known enzymatic activity (18-20). This is important as HO-1 is an intracellular enzyme and the role of its presence in the plasma is unclear. One physiological role may be in degrading excess free heme in association with hemopexin and transferrin that may result from a hemolytic or other process. Alternatively, HO-1 may be released into the plasma from smooth muscle cells, cardiomyocytes, leukocytes, monocytes/macrophages and/or endothelial cells that are damaged by the effect of hypertension, oxidative stress and/or chronic inflammation (8).

The observations described above suggest that HO-1 has a role in $\mathrm{CV}$ disease pathogenesis. However, the role of $\mathrm{HO}-1$ in PAD remains to be elucidated.

Thus, the present study aimed to measure serum levels of HO-1 and other surrogate markers of oxidative stress, including reduced glutathione, lipid hydroperoxides and isoprostanes, in patients with PAD at the time of their first diagnosis.

\section{Patients and methods}

Patients ( $n=27$; male; mean age, $66 \pm 8$ years) were enrolled consecutively and examined in the non-invasive vascular laboratory of the Medical Angiology Unit (Garibaldi Hospital, Catania, Italy). Patients were diagnosed with PAD based on their medical history of intermittent claudication and/or vasodilatation therapeutic agents, and an ankle/brachial index $(\mathrm{ABI}) \leq 0.9$. The ABI was obtained by measuring the arterial pressure at the posterior or anterior tibial of the lower limbs and was divided by the brachial arterial pressure. A pocket-sized Doppler equipped with an $8 \mathrm{MHz}$ pencil style probe (Sonomed SRL, Rome, Italy) was used to record the ABI. The lowest value observed in one of the two peripheral arteries of the lower limbs was considered. All the enrolled patients met the criteria of stage II according to the Fontaine classification of PAD, in which pain due to walking is intermittent claudication (21). The mean value of the free walking distance in all PAD patients was $347 \pm 170 \mathrm{~m}$. The mean ABI value of the PAD patients was $0.83 \pm 0.08 ; 0.85 \pm 0.7$ in less severe patients (stage IIa) and $0.78 \pm 0.5$ in the more severe patients (stage IIb). None of the PAD patients exhibited a higher ABI $(>1.3)$ than the previously mentioned values. Healthy male volunteers $(n=27)$ served as age-matched controls.

Controls were recruited from healthy volunteer blood donors, regularly attending the transfusion center of the University of Catania Hospital (Catania, Italy). Body mass index (BMI) was calculated, for patients and controls, as $\mathrm{kg} / \mathrm{m}^{2}$. Obesity was diagnosed when the BMI was $>30$. Controls were healthy individuals with no known risk factors for PAD, including diabetes or dyslipidaemia.

The adopted procedures were in agreement with the Helsinki Declaration of 1975, as revised in 1983 and were approved by the Ethics Council and Institutional Review Boards of the Garibaldi Hospital, University of Catania. All subjects provided informed consent. Participants did not suffer from recent coronary acute syndrome, heart failure, chronic or acute renal failure, active cancer, chronic liver disease or immunologic diseases.

Blood sampling. Venepuncture was conducted using an antecubital vein at the time of diagnosis and enrollment. The blood was collected in vacutainers and distributed in $0.5 \mathrm{ml}$ aliquots. The serum samples, obtained by centrifugation at $3,000 \mathrm{x} \mathrm{g}$ for $15 \mathrm{~min}$ at $4^{\circ} \mathrm{C}$, were stored at $-80^{\circ} \mathrm{C}$ until analysis (22).

Lipid hydroperoxide ( $\mathrm{LOOH}$ ) determination. $\mathrm{LOOH}$ levels were evaluated following the oxidation of $\mathrm{Fe}^{2+}$ to $\mathrm{Fe}^{3+}$ in the presence of xylenol orange (23). The assay mixture contained, in a total volume of $1 \mathrm{ml} / 100 \mathrm{ml}$ of plasma sample, $100 \mathrm{mmol} / \mathrm{l}$ xylenol orange, $250 \mathrm{mmol} / \mathrm{l}$ ammonium ferrous sulfate, $90 \%$ methanol, $4 \mathrm{mmol} / 1$ butylated hydroxytoluene and $25 \mathrm{mmol} / \mathrm{l}$ $\mathrm{H}_{2} \mathrm{SO}_{4}$. Following incubation for $30 \mathrm{~min}$ at room temperature, the absorbance was measured using a U2000 Hitachi spectrophotometer (Hitachi, Ltd., Tokyo, Japan) at a wavelength of $560 \mathrm{~nm}$. Calibration was obtained using hydrogen peroxide $(0.2-20 \mathrm{mmol} / \mathrm{l})$. The limit of detection for this assay is $\sim 0.25 \mathrm{nmol} / 1$.

Measurement of glutathione (GSH). Plasma levels of GSH were measured using a spectrophotometric assay based on the reaction of thiol groups with 2,2-dithio-bis-nitrobenzoic acid at a wavelength of $412 \mathrm{~nm}(\varepsilon M=13,600 \mathrm{M}-1 \mathrm{~cm}-1$, where $\varepsilon \mathrm{M}$ is a wavelength-dependent molar absorptivity coefficient) (23). Measurements were performed in duplicate.

Measurement of HO-1, adiponectin and isoprostanes. A commercially available HO-1 (human) ADI-EKS-800 ELISA kit (Stressgen Biotechnologies Corporation, Victoria, $\mathrm{BC}$, Canada) was used to measure HO-1 concentration. The assay was performed according to the manufacturer's protocol as previously described $(24,25)$. Briefly, each plasma sample was incubated with anti-HO-1, anti-rabbit immunoglobulin $\mathrm{G}$ and horseradish peroxidase conjugates, in successive order. Absorbance was measured at a wavelength of $450 \mathrm{~nm}$, and HO-1 concentration was calculated from a standard curve generated with purified proteins. The limit of detection as specified by the manufacturer was $0.78 \pm 0.65 \mathrm{ng} / \mathrm{ml}$. Each measurement was performed in triplicate, and means were reported. Similarly, isoprostanes and adiponectin were determined using the 8-Isoprostane ELISA kit and the adiponectin (Human) EIA kit (Cayman Chemical Company, Ann Arbor, MI, USA) according to the manufacturer's protocol.

Statistical analysis. Statistical analyses were performed using Statview ${ }^{\circledR} 5.0$ (SAS Institute Inc., Cary, NC, USA). Univariate analyses were performed using Student's unpaired t-test for numeric variables, whereas the differences in the prevalence for nominal variables were analyzed using the $\chi^{2}$ test. Correlation analyses were performed using the Pearson rank correlation method.

Multivariate analysis (by multiple regression model) was performed in order to determine the effect of clinical and laboratory parameters on the presence or severity of PAD. Two different models of multivariate analysis for the presence and for the severity of PAD were built, aiming to test whether HO-1 was an independent predictor of the presence or the severity of PAD, respectively, with the following dependent variables: HO-1, hypertension, diabetes, ABI, smoking, age, dyslipidemia, obesity and free walking distance. All data are 
Table I. Clinical and laboratory data in PAD patients and controls. Data are expressed as the mean \pm standard deviation or as percentages.

\begin{tabular}{|c|c|c|c|}
\hline Parameter & $\operatorname{PAD}(n=27)$ & $\mathrm{P}=$ & Controls $(n=27)$ \\
\hline Age, years & $66 \pm 8$ & $n s$ & $65 \pm 9$ \\
\hline BMI $\left(\mathrm{kg} / \mathrm{m}^{2}\right)$ & $29 \pm 1$ & $n s$ & $29 \pm 2$ \\
\hline Obesity (\%) & $9(33)$ & $n s$ & $9(23)$ \\
\hline Diabetes, n (\%) & $10(37)$ & - & / \\
\hline Smoking, n (\%) & $22(81)$ & $n s$ & $20(74)$ \\
\hline Dyslipidemia, n (\%) & $16(59)$ & - & / \\
\hline Hypertension, n (\%) & $19(70)$ & - & l \\
\hline Use of statins, n (\%) & $15(56)$ & - & / \\
\hline Use of aspirin, $\mathrm{n}(\%)$ & $24(89)$ & - & l \\
\hline PAD stage IIa, n (\%) & $13(48)$ & - & l \\
\hline Pain-free walking distance (meters) & $347 \pm 170$ & - & l \\
\hline Ankle-brachial index & $0.83 \pm 0.08$ & - & l \\
\hline Lipid hydroperoxides (nmol/ml) & $6.8 \pm 14.2$ & $n s$ & $8.3 \pm 14.9$ \\
\hline Glutathione (nmol/ml) & $5.1 \pm 7.6$ & $n s$ & $6.9 \pm 9.1$ \\
\hline Heme oxygenase-1 (ng/ml) & $0.8 \pm 0.7$ & $<0.0001$ & $3.4 \pm 1.3$ \\
\hline Lactic acids (mM) & $0.11 \pm 0.01$ & 0.0123 & $0.10 \pm 0.01$ \\
\hline Isoprostanes (pg/ml) & $3.8 \pm 4.8$ & $<0.0001$ & $120 \pm 91$ \\
\hline Adiponectin $(\mu \mathrm{g} / \mathrm{ml})$ & $1.4 \pm 0.2$ & $n s$ & $1.5 \pm 0.5$ \\
\hline
\end{tabular}

PAD, peripheral artery disease; ns, not significant.

Table II. Pearson correlations in peripheral artery disease patients.

\begin{tabular}{|c|c|c|c|c|c|c|}
\hline Parameter & $\mathrm{LOOH}$ & Glutathione & HO-1 & Lactic acids & Isoprostanes & Adiponectin \\
\hline Age & -.074 & -.111 & -.125 & .026 & .112 & $-.457^{a}$ \\
\hline BMI & .123 & .220 & .151 & -.304 & -.227 & -.076 \\
\hline PfWD & .084 & -.316 & .258 & -.100 & -.238 & -.178 \\
\hline $\mathrm{ABI}$ & .238 & -.359 & .057 & .001 & .104 & -.095 \\
\hline $\mathrm{LOOH}$ & - & -.194 & -.263 & .100 & .243 & -.227 \\
\hline Glutathione & -.194 & - & -.253 & $-.525^{a}$ & .045 & .016 \\
\hline HO-1 & -.263 & -.253 & - & -.061 & .009 & .190 \\
\hline Lactic acid & .100 & $-.525^{a}$ & -.061 & - & .175 & -.242 \\
\hline Isoprostanes & .243 & .045 & .009 & .175 & - & .008 \\
\hline Adiponectin & -.227 & .016 & .190 & -.242 & .008 & - \\
\hline
\end{tabular}

In bold the relationships that reached statistical significance ( $\left.{ }^{\mathrm{a}} \mathrm{P}<0.05\right)$. BMI, body mass index; PfWD, Pain-free walking distance; ABI, ankle-brachial index; LOOH, lipid hydroperoxides; HO-1, heme oxygenase-1.

expressed as mean and standard deviation. $\mathrm{P}<0.05$ was considered to indicate a statistically significant difference.

\section{Results}

The major clinical characteristics of the study subjects are summarized in Table I; the co-administration of other therapeutic agents for CV prevention was considerable, and included anti-hypertensive and lipid-lowering agents, in addition to aspirin. This was a potential limitation of the present study. As presented in Table I, no significant differences in $\mathrm{LOOH}, \mathrm{GSH}$ and adiponectin levels were observed between the PAD patients and controls. However, a significant increase in GSH level was observed in stage IIb patients when compared with stage IIa patients (Fig. 1; $\mathrm{P}<0.036)$. Furthermore, a significant decrease in plasma protein levels of HO-1 was observed in PAD patients when compared with the controls. Notably, this reduction was not dependent on the stage of the disease or levels of oxidative stress biomarkers. A multivariate analysis (multiple regression) was also performed in order to test whether HO-1 was an independent predictor of the presence or the severity of 


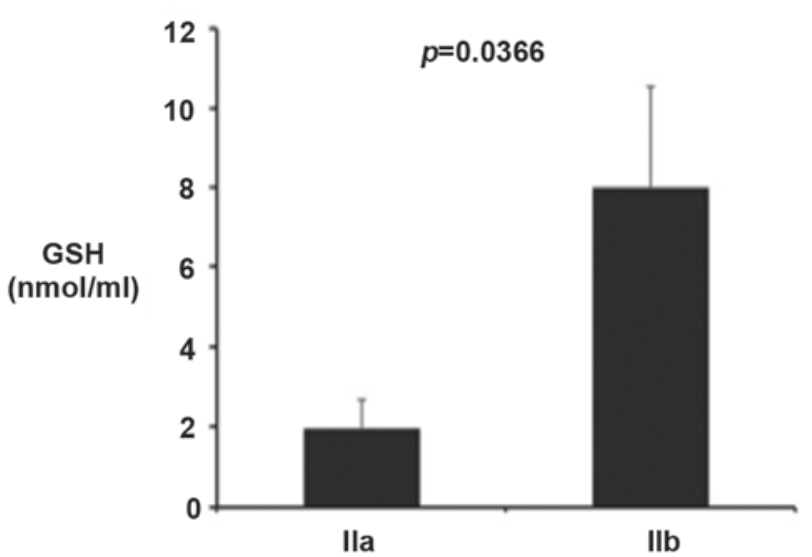

Figure 1. Association between peripheral artery disease severity and GSH. Data are expressed as the mean \pm standard error of the mean.

PAD. It was observed that HO-1, hypertension, smoking and dyslipidemia were independent predictors of the presence of PAD $(\mathrm{P}<0.0001, \mathrm{P}<0.0001, \mathrm{P}=0.0082$, and $\mathrm{P}=0.0013$ respectively). In addition, ABI was the only independent predictor of PAD severity $(\mathrm{P}<0.0001)$.

\section{Discussion}

Oxidative stress is the result of an imbalance between the generation of reactive oxygen species and the antioxidant defense system. Although appropriate epidemiological markers to measure oxidative stress are lacking, certain markers have been examined specifically with respect to PAD. In the present study, various biomarkers were evaluated to detect the level of oxidative stress.

The results of the present study indicated there was no significant difference in GSH content in PAD patients when compared with healthy controls. These data may appear inconsistent with previous data that demonstrated a marked increase in oxidative stress markers in CV disease (26). However, it should be considered that oxidative stress triggers a series of compensatory biochemical mechanisms in order to maintain the redox balance. Thus, it may be that patients increase GSH synthesis via the upregulation of its enzymatic synthesis, such as GSH reductase and gamma glutamyl cysteine synthase. The findings of the present study are consistent with this hypothesis, they indicate that GSH is increased in the group of patients with more severe disease (stage IIb) compared with the milder form. Similarly, the level of isoprostanes in stage IIb patients are not significantly different when compared with stage IIa patients, suggesting that the more severe patients exhibit a balanced maintenance of the systemic redox balance accompanied by a concomitant upregulation of GSH production. Regarding lipid peroxidation, LOOH may notably be transformed into more oxidized products, including malondialdehyde, which is a downstream product of lipid peroxidation and is not measured by the spectrophotometric assay used in the current study. Isoprostanes, the other lipid peroxidation biomarker used in the present study, may appear inconsistent with data presented in previous studies $(27,28)$. Since their identification, levels of $\mathrm{F}_{2}$-isoprostanes have been recommended as a reliable biomarker for measuring in vivo lipid oxidation and oxidative stress (27). Previous studies demonstrated higher levels of urinary 8-iso-prostaglanding $\mathrm{F}_{2 \alpha}$ in patients with chronic lower limb ischemia compared with healthy controls $(28,29)$. One previous study performed multivariate adjustment. Following adjustment for age, gender, diabetes, hypertension, BMI, creatinine, low-density lipoprotein, triglyceride, high-sensitivity C-reactive protein and homocysteine, an increment of every $10 \mathrm{pg} / \mathrm{ml}$ in plasma 8 -iso-PGF $2 \alpha$ was associated with an increased risk of $11 \%$ for lower limb ischemia (28). Furthermore, the present study also evaluated the levels of adiponectin in PAD patients and healthy controls. Results from the present study indicated there was no significant difference in adiponectin levels between the two groups, however, a previous study (30) demonstrated that low adiponectin levels were associated with an increase in PAD incidence.

The current study indicated there was a significant reduction in HO-1 levels in PAD patients when compared with healthy controls. The protective properties of $\mathrm{HO}-1$ are multifactorial and likely due to degradation of pro-oxidant heme, the generation of antioxidant biliverdin and bilirubin, and the production of carbon monoxide, which is a potent vasodilator with anti-inflammatory effects $(7,9)$. Furthermore, previous studies have also observed reduced serum HO-1 in lung disease (31). The presence of HO-1 has recently been demonstrated in various intracellular and extracellular compartments, suggesting that this protein may exhibit other functions independently of its known enzymatic activity $(18,20,32)$. This latter point is important as HO-1 is an intracellular enzyme, thus, the underlying reason for its presence in the plasma is unclear. Data from the present study demonstrates that $\mathrm{HO}-1$ reduction is not dependent on other covariables and, in particular, oxidative stress parameters (Table II). In this context, it may be hypothesised that as our previous data indicated that $\mathrm{HO}-1$ protein expression is reduced in experimental diabetes and as the majority of PAD patients in the current study also had diabetes, reduced HO-1 levels in PAD may reflect reduced intracellular HO-1 content in this group (33). In addition, previous studies have also reported that $\mathrm{HO}-1$ deletion in mice evokes resistance to diet-induced insulin resistance and inflammation, markedly reducing secondary diseases, including steatosis and liver toxicity $(34,35)$. Multivariate analyses were also performed in order to test whether HO-1 was an independent predictor of the presence or severity of PAD. It was observed that HO-1 was independently associated with the presence of PAD. Furthermore, hypertension, smoking and dyslipidemia were also independent predictors of the presence of PAD, while ABI was the only independent predictor of PAD severity. These findings suggest that HO-1 may be useful in determining the presence of PAD.

Therefore, it is possible to hypothesise that plasma HO-1 reduction may also be part of the compensatory mechanisms to maintain the cellular redox status. However, the sample size of the cohort in the present study is small and this may represent a potential limitation of the data, which is required to be confirmed on a larger population.

In conclusion, the results of the present study indicate that oxidative stress depends on the stage of PAD and that the condition is followed by a concomitant antioxidant response, 
which, however, is only partially sufficient to maintain the redox balance. These findings suggest a biological basis for antioxidants, such as polyphenols, to be tested as therapeutic agents in appropriately designed prospective trials.

\section{References}

1. Abdulhannan P, Russell DA and Homer-Vanniasinkam S Peripheral arterial disease: A literature review. Br Med Bull 104: 21-39, 2012.

2. Hirsch AT, Halverson SL, Treat-Jacobson D, Hotvedt PS, Lunzer MM, Krook S, Rajala S and Hunninghake DB: The minnesota regional peripheral arterial disease screening program: Toward a definition of community standards of care. Vasc Med 6: 87-96, 2001.

3. Ramos R, Quesada M, Solanas P, Subirana I, Sala J, Vila J, Masiá R, Cerezo C, Elosua R, Grau M, et al: Prevalence of symptomatic and asymptomatic peripheral arterial disease and the value of the ankle-brachial index to stratify cardiovascular risk. Eur J Vasc Endovasc Surg 38: 305-311, 2009.

4. Ostchega Y, Paulose-Ram R, Dillon CF, Gu Q and Hughes JP: Prevalence of peripheral arterial disease and risk factors in persons aged 60 and older: Data from the National Health and Nutrition Examination Survey 1999-2004. J Am Geriatr Soc 55: 583-589, 2007.

5. Krishna SM, Moxon JV and Golledge J: A review of the pathophysiology and potential biomarkers for peripheral artery disease. Int J Mol Sci 16: 11294-11322, 2015.

6. Siti HN, Kamisah Y and Kamsiah J: The role of oxidative stress, antioxidants and vascular inflammation in cardiovascular disease (a review). Vascul Pharmacol 71: 40-56, 2015.

7. Barbagallo I, Galvano F, Frigiola A, Cappello F, Riccioni G, Murabito P, D'Orazio N, Torella M, Gazzolo D and Li Volti G: Potential therapeutic effects of natural heme oxygenase-1 inducers in cardiovascular diseases. Antioxid Redox Signal 18 : 507-521, 2013

8. Novo G, Cappello F, Rizzo M, Fazio G, Zambuto S, Tortorici E, Marino Gammazza A, Corrao S, Zummo G, De Macario EC, et al Hsp60 and heme oxygenase-1 (Hsp32) in acute myocardial infarction. Transl Res 157: 285-292, 2011.

9. Barbagallo I, Nicolosi A, Calabrese G, David S, Cimino S, Madonia M and Cappello F: The role of the heme oxygenase system in the metabolic syndrome. Curr Pharm Des 20: 4970-4974, 2014.

10. Li Volti G, Sacerdoti D, Di Giacomo C, Barcellona ML, Scacco A, Murabito P, Biondi A, Basile F, Gazzolo D, Abella R, et al: Natural heme oxygenase-1 inducers in hepatobiliary function. World J Gastroenterol 14: 6122-6132, 2008.

11. Li Volti G, Sorrenti V, Murabito P, Galvano F, Veroux M, Gullo A, Acquaviva R, Stacchiotti A, Bonomini F, Vanella L and Di Giacomo C: Pharmacological induction of heme oxygenase-1 inhibits iNOS and oxidative stress in renal ischemia-reperfusion injury. Transplant Proc 39: 2986-2991, 2007.

12. Li Volti G, SetaF, Schwartzman ML, Nasjletti A and Abraham NG: Heme oxygenase attenuates angiotensin II-mediated increase in cyclooxygenase-2 activity in human femoral endothelial cells. Hypertension 41: 715-719, 2003

13. Kushida T, LiVolti G, Goodman AI and Abraham NG: TNF-alpha-mediated cell death is attenuated by retrovirus delivery of human heme oxygenase-1 gene into human microvessel endothelial cells. Transplant Proc 34: 2973-2978, 2002.

14. Sacerdoti D, Colombrita C, Ghattas MH, Ismaeil EF, Scapagnini G, Bolognesi M, Li Volti G and Abraham NG: Heme oxygenase-1 transduction in endothelial cells causes downregulation of monocyte chemoattractant protein-1 and of genes involved in inflammation and growth. Cell Mol Biol (Noisy-le-grand) 51: 363-370, 2005.

15. Marrazzo G, Bosco P, La Delia F, Scapagnini G, Di Giacomo C, Malaguarnera M, Galvano F, Nicolosi A and Li Volti G: Neuroprotective effect of silibinin in diabetic mice. Neurosci Lett 504: 252-256, 2011

16. Li Volti G, Sacerdoti D, Sangras B, Vanella A, Mezentsev A, Scapagnini G, Falck JR and Abraham NG: Carbon monoxide signaling in promoting angiogenesis in human microvessel endothelial cells. Antioxid Redox Signal 7: 704-710, 2005.
17. Li Volti G, Wang J, Traganos F, Kappas A and Abraham NG: Differential effect of heme oxygenase-1 in endothelial and smooth muscle cell cycle progression. Biochem Biophys Res Commun 296: 1077-1082, 2002.

18. Tibullo D, Barbagallo I, Giallongo C, La Cava P, Parrinello N, Vanella L, Stagno F, Palumbo GA, Li Volti G and Di Raimondo F: Nuclear translocation of heme oxygenase-1 confers resistance to Imatinib in chronic myeloid leukemia cells. Curr Pharm Des 19: 2765-2770, 2013

19. Rizzo M, Abate N, Chandalia M, Rizvi AA, Giglio RV, Nikolic D, Marino Gammazza A, Barbagallo I, Isenovic ER, Banach M, et al: Liraglutide reduces oxidative stress and restores heme oxygenase-1 and ghrelin levels in patients with type 2 diabetes: A prospective pilot study. J Clin Endocrinol Metab 100: 603-606, 2015.

20. Li Volti G, Galvano F, Frigiola A, Guccione S, Di Giacomo C, Forte S, Tringali G, Caruso M, Adekoya OA and Gazzolo D: Potential immunoregulatory role of heme oxygenase- 1 in human milk: A combined biochemical and molecular modeling approach. J Nutr Biochem 21: 865-871, 2010.

21. Fontaine R, Kim M and Kieny R: Surgical treatment of peripheral circulation disorders. Helv Chir Acta 21: 499-533, 1954 (In German).

22. Malaguarnera M, Vacante M, Giordano M, Pennisi G, Bella R, Rampello L, Malaguarnera M, Li Volti G and Galvano F: Oral acetyl-L-carnitine therapy reduces fatigue in overt hepatic encephalopathy: A randomized, double-blind, placebo-controlled study. Am J Clin Nutr 93: 799-808, 2011.

23. Nibali L, Rizzo M, Li Volti G, D'Aiuto F, Giglio RV, Barbagallo I, Pelekos G and Donos N: Lipid subclasses profiles and oxidative stress in aggressive periodontitis before and after treatment. J Periodontal Res 50: 890-896, 2015.

24. Li Volti G, Musumeci T, Pignatello R, Murabito P, Barbagallo I, Carbone C, Gullo A and Puglisi G: Antioxidant potential of different melatonin-loaded nanomedicines in an experimental model of sepsis. Exp Biol Med (Maywood) 237: 670-677, 2012.

25. Li Volti G, Salomone S, Sorrenti V, Mangiameli A, Urso V, Siarkos I, Galvano F and Salamone F: Effect of silibinin on endothelial dysfunction and ADMA levels in obese diabetic mice. Cardiovasc Diabetol 10: 62, 2011.

26. Rani V, Deep G, Singh RK, Palle K and Yadav UC. Oxidative stress and metabolic disorders: Pathogenesis and therapeutic strategies. Life Sci 148: 183-193, 2016.

27. Niki E: Biomarkers of lipid peroxidation in clinical material. Biochim Biophys Acta 1840: 809-817, 2014.

28. Rossi P, Riutta A, Kuukasjärvi P, Vehmas T, Mucha I and Salenius JP: Revascularization decreases 8-isoprostaglandin F2alpha excretion in chronic lower limb ischemia. Prostaglandins Leukot Essent Fatty Acids 71: 97-101, 2004

29. Liang Y, Wei P, Duke RW, Reaven PD, Harman SM, Cutler RG, Heward CB. Quantification of 8-iso-prostaglandin-F(2alpha) and 2,3-dinor-8-iso-prostaglandin-F(2alpha) in human urine using liquid chromatography-tandem mass spectrometry. Free Radic Biol Med 34: 409-418, 2003.

30. Ho DY, Cook NR, Britton KA, Kim E, Creager MA, Ridker PM and Pradhan AD: High-molecular-weight and total adiponectin levels and incident symptomatic peripheral artery disease in women: A prospective investigation. Circulation 124: 2303-2311, 2011.

31. Sato T, Saito Y, Inoue S, Shimosato T, Takagi S, Kaneko T and Ishigatsubo Y: Serum heme oxygenase-1 as a marker of lung function decline in patients with chronic silicosis. J Occup Environ Med 54: 1461-1466, 2012.

32. Lin Q, Weis S, Yang G, Weng YH, Helston R, Rish K, Smith A, Bordner J, Polte T, Gaunitz F and Dennery PA: Heme oxygenase-1 protein localizes to the nucleus and activates transcription factors important in oxidative stress. J Biol Chem 282: 20621-20633, 2007.

33. Abraham NG, Rezzani R, Rodella L, Kruger A, Taller D, Li Volti G, Goodman AI and Kappas A: Overexpression of human heme oxygenase-1 attenuates endothelial cell sloughing in experimental diabetes. Am J Physiol Heart Circ Physiol 287: H2468-H2477, 2004.

34. Jais A, Einwallner E, Sharif O, Gossens K, Lu TT, Soyal SM, Medgyesi D, Neureiter D, Paier-Pourani J, Dalgaard K, et al: Heme oxygenase-1 drives metaflammation and insulin resistance in mouse and man. Cell 158: 25-40, 2014.

35. Huang JY, Chiang MT, Yet SF and Chau LY: Myeloid heme oxygenase-1 haploinsufficiency reduces high fat diet-induced insulin resistance by affecting adipose macrophage infiltration in mice. PLoS One 7: e38626, 2012. 